\title{
Laboratory Experimental Laws for the Radon Exhalation of Similar Uranium Samples with Low-Frequency Vibrations
}

\author{
Zi-qi Cai ${ }^{1,2}$, Xiang-yang Li ${ }^{1,2, *}$, Bo Lei ${ }^{1, *}$, Jing-fan Yuan ${ }^{1}$, Chang-shou Hong ${ }^{2}$ and Hong Wang ${ }^{2}$ \\ 1 School of Environment and Safety Engineering, University of South China, Hengyang 421001, China; \\ 201523611052@usc.edu.cn (Z.-q.C); 201721620654@usc.edu.cn (J.-f.Y) \\ 2 Hunan Province Engineering Technology Research Center of Uranium Tailings Treatment, \\ University of South China, Hengyang 421001, China; 360003802790@usc.edu.cn (C.-s.H); \\ 14100045@usc.edu.cn (H.W) \\ * Correspondence: 430005773240@usc.edu.cn (X.-y.L.); hame88@usc.edu.cn (B.L.)
}

Received: 30 May 2018; Accepted: 7 August 2018; Published: 18 August 2018

\begin{abstract}
It is the fact that there are lots of hazard incidents in underground uranium mines caused by radon but in-suit uranium samples were difficult to collect. Based on closed chamber method, three similar samples in different sealed ways were made in a laboratory with different material rations, namely uranium tailings, quartz sand, cement, iron powder and silicon powder to measure the radon concentrations with and without low-frequency vibrations, which was used by the experimental device for low-frequency vibration diffusion of radon. The results showed that the radon exhalation coming from the similar samples was influenced by the low frequency vibration; the results are presented as two-stage variations compared with the blank group. The radon exhalation increased with the rising vibration frequency when the frequency was $50 \mathrm{to} 70 \mathrm{~Hz}$, but fell slowly after reaching the peak radon exhalation rate. Analyses of the relations between the rock damage degree, changes in porosity and the occurrence of an inflection point in the radon exhalation rate in the samples found that they also increased when the frequency was between 0 to 80 in sample 3. The maximum porosity of the third samples was about $4.8 \%$ with a low-frequency vibration $60 \mathrm{~Hz}$, while the maximum damage degree was about 0.07 at $50 \mathrm{~Hz}$.
\end{abstract}

Keywords: uranium; similar materials; low-frequency vibration; radon exhalation rate; porosity

\section{Introduction}

A uranium mine shaft is a special and open workplace that connects with radioactive materials, however, these tunnels have many characteristics, such as floating uranium mine ash, radon exhalation, high concentrations of radon and related materials, and low safety conditions for radiation [1]. It is widely accepted that free radon can exhale into the air from the uranium rock surface through diffusion and seepage [2]. Pores or micro-fissures in rocks are the tunnels through which radon is transported in the rock, and diffusion and seepage provide the main momentum for radon transport. The number, volume, and degree of openness and expansion of pores or micro-fissures are closely related to the geomechanical environment, such as underground water seepage fields, in-situ stress fields, ultrasonic vibration fields, low-vibration fields, and temperature fields [3-5]. However, the mechanisms of diffusion and seepage are influenced by internal and external factors, such as the pore structure, temperature and water content of the soil [6-8]. Therefore, the whole process of the transportation of radon through the rock and soil and on the surface is in close relation with the surrounding rock and soil. It has been demonstrated that the degree of damage of the rock and 
the expansion of micro-fissures due to fatigue related to the rock's kinetic response characteristics, the frequency of vibrations, and other rock characteristics [9].

It has been found that there is a lot of random initial damage to rocks such as micro-fissures and joints; rocks near the core can produce new fractures due to crustal movement, and simultaneously fractures and joints in rocks can expand increasingly, becoming the main fracture of the sample under a stress wave $[10,11]$. The disturbance of low-frequency vibrations is an impact factor that leads to pores and micro-fissures in rocks and soil, also leading indirectly to the exhalation of radon and related materials from the test blocks of uranium ore. Abnormal exhalation results from the blasting of uranium mining [12], earthquakes [13], and other geological calamities [14]. The frequency range of vibrations is shown as inducing factors in Table 1. The major frequencies of the vibrations produced by chamber blasting are normally 7 to 20 hertz [15]. The range of the excitation frequency is 0 to 27 hertz for earthquakes in uranium mining areas, according to the earthquake kinetics parameters in the 'Seismic Ground Motion Parameters Zoning Map of China (GB 18306-2015)' [16] and the 'Safety Requirements for the Decommissioning of Nuclear Facilities (GB/T19597-2004)' [17]. Above all, the frequencies used in mining belong to the range of low-frequency vibrations. The relation between radon concentrations and earthquake stress has been studied to analyze the change of eight non-linear parameters of earthquakes; this study used a self-learning artificial neural network and had an error from $0 \%$ to $12 \%$ [18]. Experimental research has studied the relation between the characteristics of acoustic emissions in deep ore fractures and radon exhalation [19]. The relation between radon concentrations and the seismic zone has been analyzed to show the functional migration of radon concentrations under the impact of earthquakes [20].The law of radon exhalation was studied under low-frequency vibration in the deep uranium shaft using the measurement device independently to test the radon concentration and applying the software and detectors to analyze the radon exhalation rate and damage analysis. This article is an experimental analysis of the abnormal exhalation mechanisms of radon in similar uranium samples under low frequency vibrations; the scientific evidence is supported by the experiment of deep uranium mining.

Table 1. The regular frequency of vibrations in uranium mining.

\begin{tabular}{cccccccc}
\hline \multirow{2}{*}{$\begin{array}{c}\text { Mining } \\
\text { Operation Factor }\end{array}$} & $\begin{array}{c}\text { Medium-Length } \\
\text { Hole Blasting }\end{array}$ & $\begin{array}{c}\text { Shallow Hole } \\
\text { Blasting }\end{array}$ & $\begin{array}{c}\text { Wenchuan } \\
\text { Quake Wave }\end{array}$ & $\begin{array}{c}\text { Darui } \\
\text { Synthetic Wave }\end{array}$ & $\begin{array}{c}\text { Kobe } \\
\text { Seismic }\end{array}$ & $\begin{array}{c}\text { Drilling } \\
\text { Jumbo }\end{array}$ & $\begin{array}{c}\text { Shovel } \\
\text { Car }\end{array}$ \\
\hline $\begin{array}{c}\text { Vibration } \\
\text { frequency }(\mathrm{Hz})\end{array}$ & $10 \sim 60$ & $9 \sim 48$ & $5 \sim 27$ & $4 \sim 12$ & $1 \sim 25$ & $10 \sim 50$ & 50 \\
\hline
\end{tabular}

\section{Theory and Materials}

\subsection{The Radon Exhalation}

According to the diffusive migration law of radon, the measured radon concentration of each sample in the closed chamber method was obtained using a RAD7 Electronic Radon Detector, while at the same time using the Origin9 software to obtain the slopes $k_{1}$ and $k_{2}$ of the fitting calculation. Finally, the radon exhalation rate by sample was calculated using the following equation:

$$
J_{1}=\frac{k_{1} \cdot V_{e}}{S_{1}} ; J_{2}=\frac{k_{2} \cdot V_{e}}{S_{2}}
$$

where $J_{1}$ and $J_{2}$ are the radon exhalation rate of single-sided and double-sided sample $\left(\mathrm{Bq} \cdot \mathrm{m}^{-2} \cdot \mathrm{s}^{-1}\right)$; $k_{1}$ and $k_{2}$ are the radon exhalation slope of fitting curves using the single-sided and double-sided sample $\left(\mathrm{Bq} \cdot \mathrm{m}^{-3} \cdot \mathrm{s}^{-1}\right) ; S_{1}$ and $S_{2}$ are the side areas when the sample is exposed on single-sided and double-sided $\left(\mathrm{m}^{2}\right)$; a schematic diagram of samples wrapping modes is shown in Figure 1; Obviously, $\mathrm{S} 2=2 \mathrm{~S} 1, V_{e}$ is the effective volume of the inside of the tank in addition to the sample $\left(\mathrm{m}^{3}\right)$. 


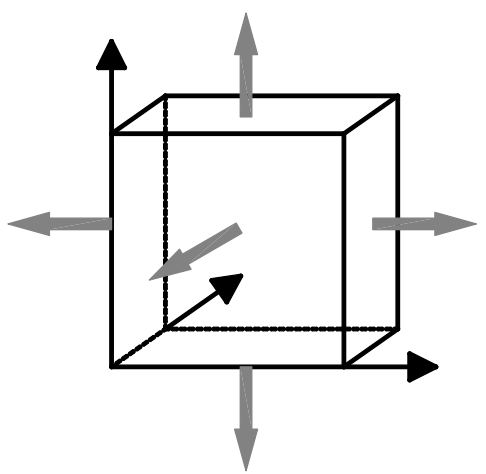

(1)

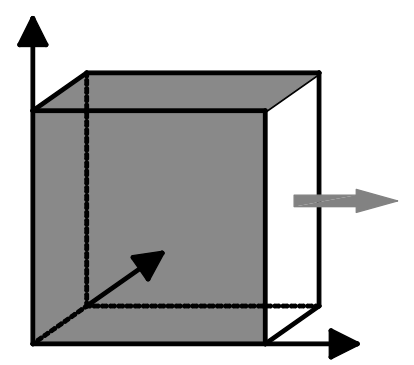

(2)

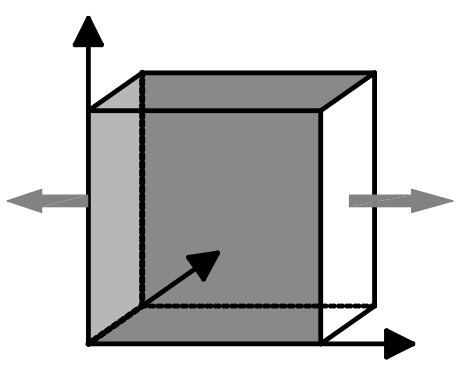

(3)

Figure 1. Fully-exposed (1) single-side exposed (2) double-side exposed (3) similar uranium samples.

According to Equation (1) and the sample's package processing method, the theoretical expression of the radon exhalation rate was calculated using the following equation:

Single-sided sample:

$$
J_{1}=D \frac{d}{d x} C_{\mid x=0}=\left(J_{0}-\sqrt{\lambda \eta D} C_{0}\right) \tanh \left(\sqrt{\frac{\lambda \eta}{D}} h\right)
$$

Double-sided sample:

$$
\begin{aligned}
J_{2}=D \frac{d}{d x} C_{\mid x=0} & =\left(J_{0}-\sqrt{\lambda \eta D} C_{0}\right) \tanh \left(\frac{1}{2} \sqrt{\frac{\lambda \eta}{D}} h\right) \\
J_{0} & =\sqrt{\lambda \eta D} \frac{C_{\mathrm{Ra}} S_{\mathrm{e}} \rho}{\eta}
\end{aligned}
$$

where $J_{0}$ is the natural radon exhalation rate $\left(\mathrm{Bq} \cdot \mathrm{m}^{-2} \cdot \mathrm{s}^{-1}\right)$, which expresses the radon exhalation rate by sample when the radon concentration on the outer surface of an infinite thickness and indefinite extension is 0 ; it is only related to the characteristics of the material, $\rho$ is the density of the sample $\left(\mathrm{kg} \cdot \mathrm{m}^{-3}\right) ; \lambda$ is the effective decay constant of the radon $\left(2.1 \times 10^{-6} \cdot \mathrm{s}^{-1}\right), C_{\mathrm{Ra}}$ is the radium content $\left(\mathrm{Bq} \cdot \mathrm{kg}^{-1}\right), S_{\mathrm{e}}$ is the emanation coefficient, $\eta$ is the porosity of sample, $D$ is the radon diffusion coefficient of sample $\left(\mathrm{m}^{2} \cdot \mathrm{s}^{-1}\right), J_{1}$ and $J_{2}$ can be obtained according to the given conditions based on Equations (1)-(4).

$$
\frac{J_{1}}{J_{2}}=\frac{\tan (h / L)}{\tanh \left(\frac{1}{2} h / L\right)}=\frac{2 k_{1}}{k_{2}}
$$

\subsection{The Porosity}

The average porosity $\varphi$ of similar uranium samples for the experiment was calculated using the following expression [21]:

$$
\varphi=\frac{V_{e}}{V} \times 100 \%=\left(1-\frac{\rho_{e}}{\rho}\right) \times 100 \%
$$

where $\varphi$ is the total porosity of the experimental similar uranium samples (\%), $V_{e}$ is the total porosity volume of sample $\left(\mathrm{m}^{3}\right), V$ is the total volume of sample $\left(\mathrm{m}^{3}\right), \rho_{e}$ is the dry density of sample $\left(\mathrm{g} \cdot \mathrm{cm}^{-3}\right)$, $\rho$ is the particle density of sample $\left(\mathrm{g} \cdot \mathrm{cm}^{-3}\right)$. 


\subsection{Similar Samples}

According to analysis of the proportion of similar materials by rock in recent years [22-24], quartz sand, cement, calcium carbonate, gypsum, ultrafine barite powder, water, and admixtures were used as the raw materials for preparation.

In view of the fact that the main types of uranium deposit in South China belong to granite type uranium ore rocks, this paper took granite-type similar uranium samples as the simulation object and the granite protolith as the physical and mechanical property contrast prototype material. Comprehensive analysis was carried out of the function and role of various raw materials, with the selected raw materials including: uranium tailings (aggregate) with a particle size of less than $4.75 \mathrm{~mm}$, quartz sand with a particle size of 0.60 to $4.75 \mathrm{~mm}$, cement (cementing material), micro-silicon powder and iron powder (admixture), admixture (early strength agent and water reducing agent), water. Through reviewing the relative literature data, the three matching ratios were finally determined in Table 2 and the final preparation samples are shown in Figure 2.

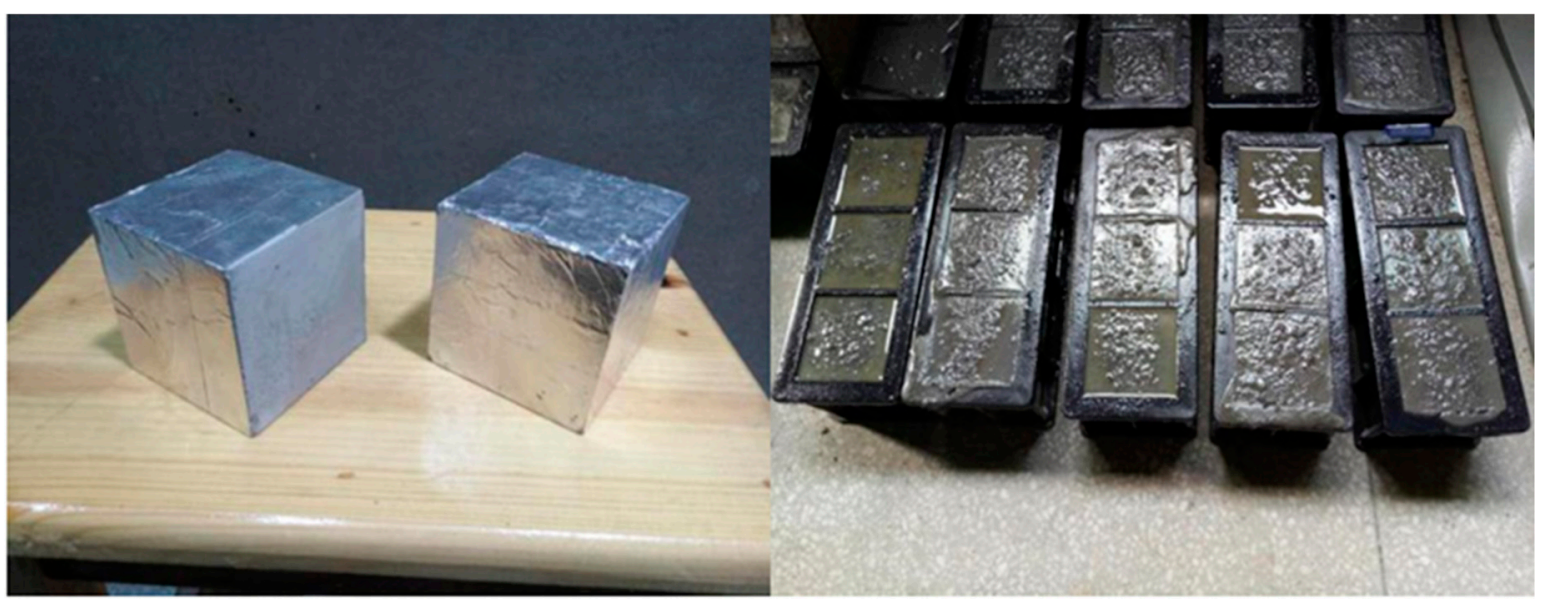

Figure 2. Single-side and double-side treatment of the end surface of the sample, $70.7 \times 70.7 \times 70.7 \mathrm{~mm}$ PVC tube and maintenance of the similar uranium samples.

Table 2. The material ratio of the three kinds of sample.

\begin{tabular}{ccccc}
\hline Test Plan & Water Cement Ratio & Sand-Binder Ratio & Micro Silicon Powder & Iron Powder \\
\hline Sample 1 & 0.28 & 1.00 & 0.09 & 0.20 \\
Sample 2 & 0.28 & 1.20 & 0.12 & 0.25 \\
Sample 3 & 0.30 & 1.20 & 0.06 & 0.20 \\
\hline
\end{tabular}

In the above three ratios, the water reducing agent was cement $=1: 50$, and the early strength agent was cement $=1: 100$. The micro-silicon powder and iron powder are the percentage of the total mass incorporated during the preparation process in order to make the sample density close to 1:1 with the prototype material density.

Considering the previous technology, the radon concentration was measured using a RAD-7 radon detector (which was demarcated by the Radon Laboratory of USC) and the low-frequency vibration was created using a vibration exciter (Type: JZK-30), piezoelectric transducer (used to monitor the change of exciting stress), a radon exhalation tank (which consists of a radon collecting space, temperature control module, and the fixing device of the sample), and desiccant; the experimental device is shown in Figure 3. The damage degree of the rock was tested and calculated after the test by using a non-metallic ultrasonic testing device (shown in Figure 4). 

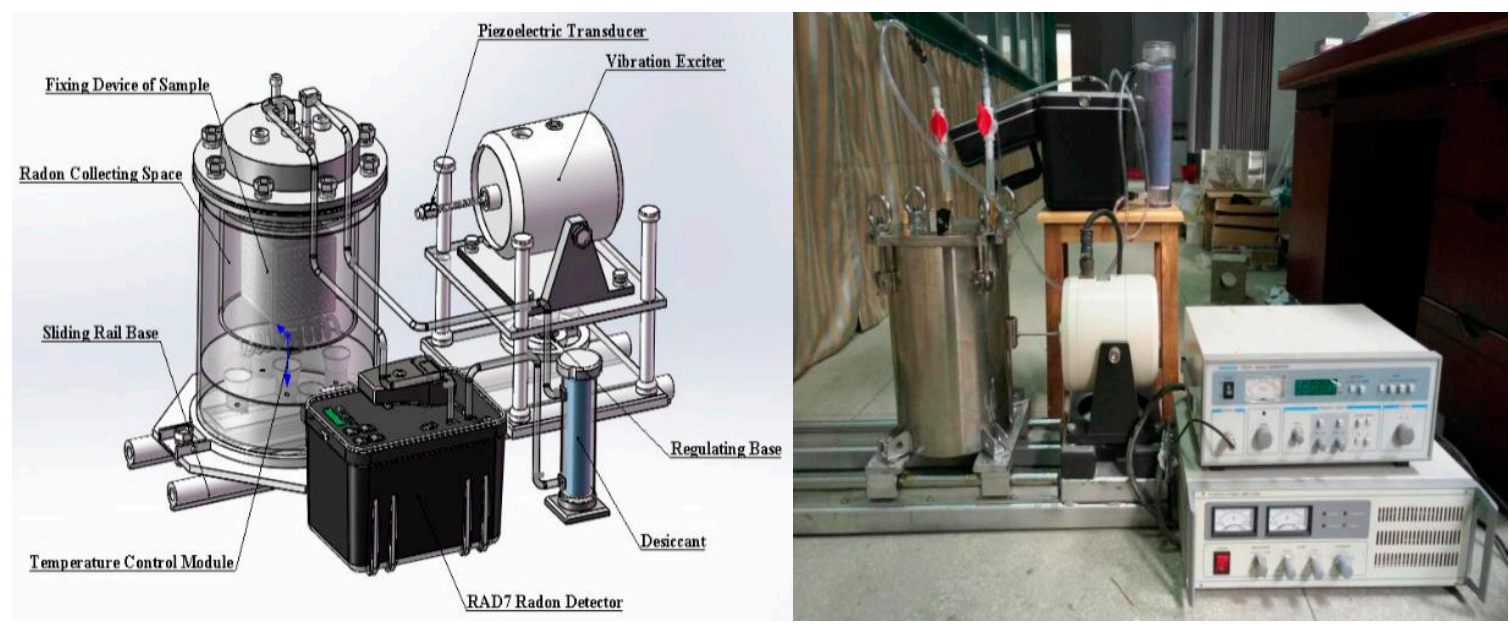

Figure 3. Experimental device for the low-frequency vibration diffusion of radon.
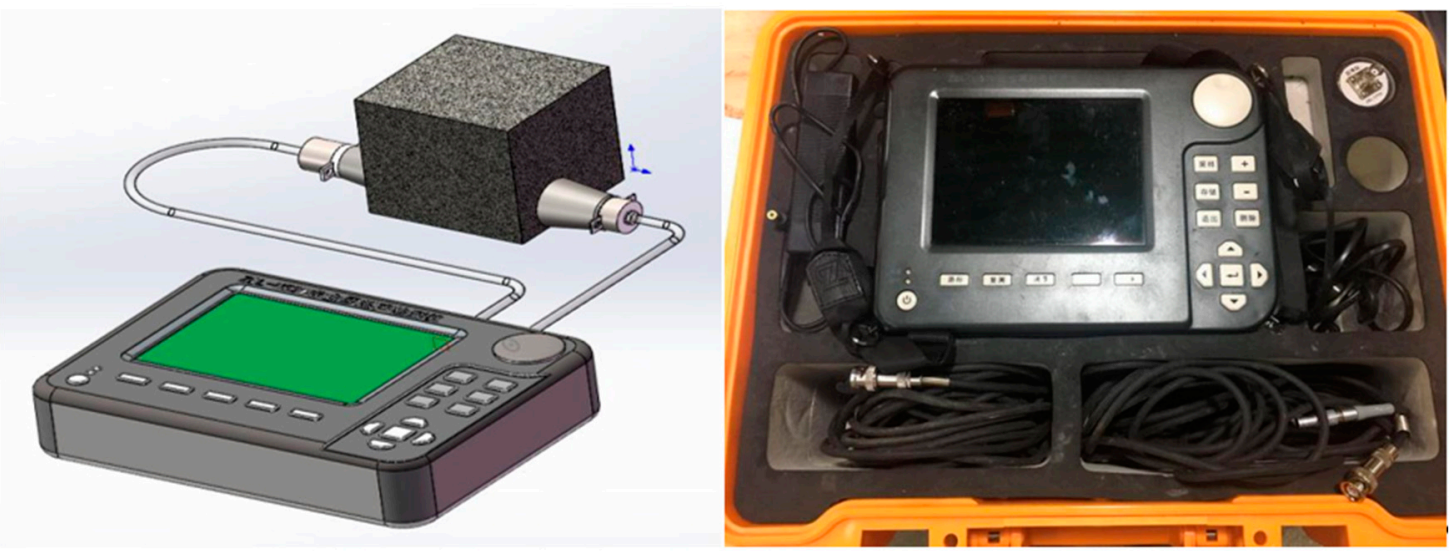

Figure 4. Non-metallic ultrasonic testing device (ZBL-U520).

\subsection{Trial Procedures}

The specific measurement procedures for the radon concentrations of the quasi-uranium ore sample were as follows:

(1) Check the tightness of the device and commission the system.

(2) The temperature of the radon-collecting space is heated to $30^{\circ} \mathrm{C}$ by starting the module. The space is purified for $30 \mathrm{~min}$ by turning on the purge function of RAD 7. According to the test plan, the wrapped single-sided exposed or double-sided exposed sample is installed on the fixed device and put into the radon exhalation tank.

(3) The vibration frequency of the exciter is set according to the plan. Every test group is set for 200 pieces of data, of which each piece of data is obtained after $5 \mathrm{~min}$ by starting the RAD 7 to record. At the end of the experiment, the samples were taken out and the ambient temperature, humidity and atmospheric pressure were measured in real time, and the corresponding test data were recorded at the same time.

(4) The change of the exciting force is monitored by using the piezoelectric sensors. First, the test sample is divided into four detection areas using the fluorescence pen, then the two sensors of the non-metallic ultrasonic testing device are pressed onto the two sides of the sample respectively by using a special adhesive, each test time is $30 \mathrm{~s}$, and the data are recorded after the test. The damage degree of the rock is tested and calculated after the test by using a non-metallic ultrasonic testing device. 


\section{Results}

\subsection{Similar Samples}

According to the above ratio, the raw materials such as aggregate, cementing material, admixture and water were added into the mixer. This was stirred well and poured into the prepared PVC mold and placed on the shaking table, eventually, a cubic similar uranium sample with a size of $70.7 \times 70.7 \times 70.7 \mathrm{~mm}$ was obtained. Subsequently, the physical and mechanical properties of the maintenance-completed similar uranium samples and granite were tested, and the physical, mechanical and radioactive parameters of the samples were obtained, as shown in Table 3. In addition, the similarity ratio of the physical and mechanical indexes between prototype and sample is shown in Table 4.

Table 3. Physical and mechanical properties of samples.

\begin{tabular}{|c|c|c|c|c|c|c|c|c|}
\hline Test Plan & $\begin{array}{l}\text { Compressive } \\
\text { Strength/MPa }\end{array}$ & $\begin{array}{l}\text { Tensile } \\
\text { Strength } \\
\text { (MPa) }\end{array}$ & $\begin{array}{l}\text { Particle } \\
\text { Density/ } \\
\left(\mathrm{g} \cdot \mathrm{cm}^{-3}\right)\end{array}$ & $\begin{array}{l}\text { Cohesion } \\
\text { (MPa) }\end{array}$ & $\begin{array}{l}\text { Internal } \\
\text { Friction } \\
\text { Angle }\left(^{\circ}\right)\end{array}$ & $\begin{array}{c}\text { Dry } \\
\text { Density/ } \\
\left(\mathrm{g} \cdot \mathrm{cm}^{-3}\right)\end{array}$ & $\begin{array}{l}\text { Radium } \\
\text { Content } \\
\left(\mathrm{Bq} \cdot \mathrm{g}^{-1}\right)\end{array}$ & $\begin{array}{l}\text { Percentage } \\
\text { of Uranium } \\
\text { Mass (\%) }\end{array}$ \\
\hline Sample 1 & 62.9 & 3.67 & 2.42 & 16.03 & 51.36 & 2.301 & 1.57 & 0.0071 \\
\hline Sample 2 & 71.2 & 4.12 & 2.49 & 15.91 & 50.44 & 2.365 & 1.72 & 0.0068 \\
\hline Sample 3 & 53.4 & 3.53 & 2.46 & 14.55 & 54.21 & 2.290 & 1.78 & 0.0085 \\
\hline $\begin{array}{l}\text { The original } \\
\text { sample of } \\
\text { granite }\end{array}$ & 206.86 & 13.23 & 2.62 & 49.52 & 48.60 & 2.415 & 0.073 & 0.03 \\
\hline
\end{tabular}

Table 4. Similarity ratio of physical-mechanical indices between prototype and samples.

\begin{tabular}{cccccc}
\hline Test Plan & $C_{p}$ & $C_{R c}$ & $C_{P t}$ & $C_{C}$ & $C_{\sigma}$ \\
\hline Sample 1 & 1.09 & 4.93 & 4.45 & 3.30 & 1.16 \\
Sample 2 & 1.11 & 3.17 & 4.50 & 3.55 & 0.94 \\
Sample 3 & 1.08 & 4.07 & 3.93 & 3.57 & 0.94 \\
\hline
\end{tabular}

$C_{p}, C_{R c}, C_{P t}, C_{C}$ and $C_{\sigma}$ are the particle density, compressive strength, tensile strength, cohesive and the ratio of the angle of internal friction to the specimen prototype.

According to the relevant data in Tables 3 and 4: The ratio of the particle density and internal friction angle between the granite prototype and three types of similar uranium samples was close to 1:1.The similar ratios of compressive strength, tensile strength and cohesion were about 3.9:1, 4.3:1 and 3.5:1. According to the three test plans, the physical and mechanical parameters of sample 3 were the closest to those of the granite prototype on the whole. From the point of view of the radioactivity index, the uranium content in the granite rock was larger than the three kinds of test samples, but the radium content was the opposite, because at least $95 \%$ of the radium in raw ores is retained in tailings, and the radium content was very small.

\subsection{Radon Concentration and Time}

According to the above experimental device, method and procedure, through a series of experiments the change curves of the radon concentration according to the time of collection were obtained from exposed samples with three proportions of similar uranium samples with different ratios. As shown in Figures 5 and 6, three types of similar uranium samples produced one piece of data every $5 \mathrm{~min}$. 


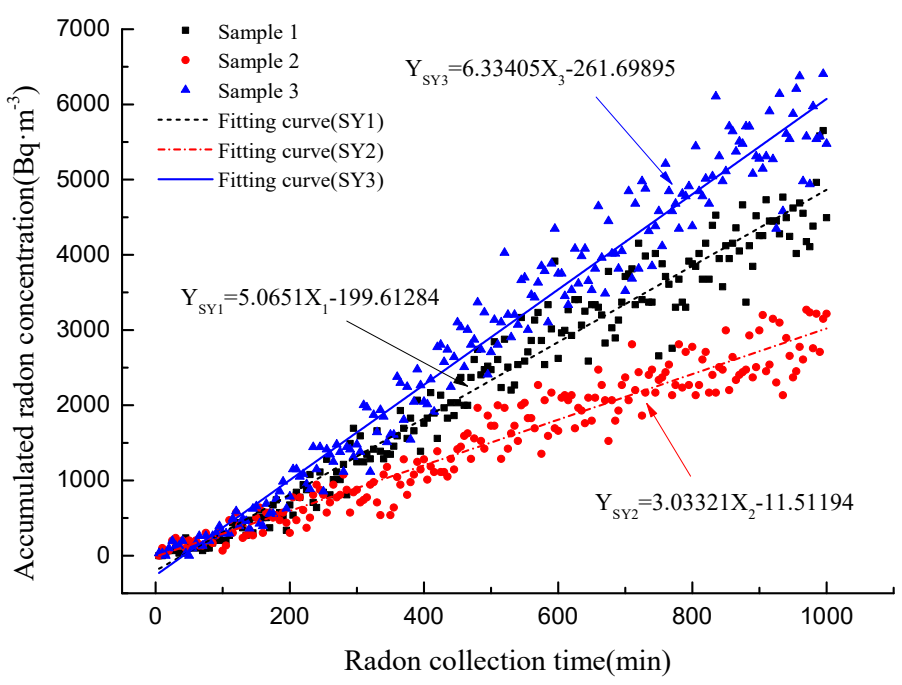

Figure 5. The variation curves of radon concentration and collection time from single-sided similar uranium samples with different proportions with a blank control group $(0 \mathrm{~Hz})$.

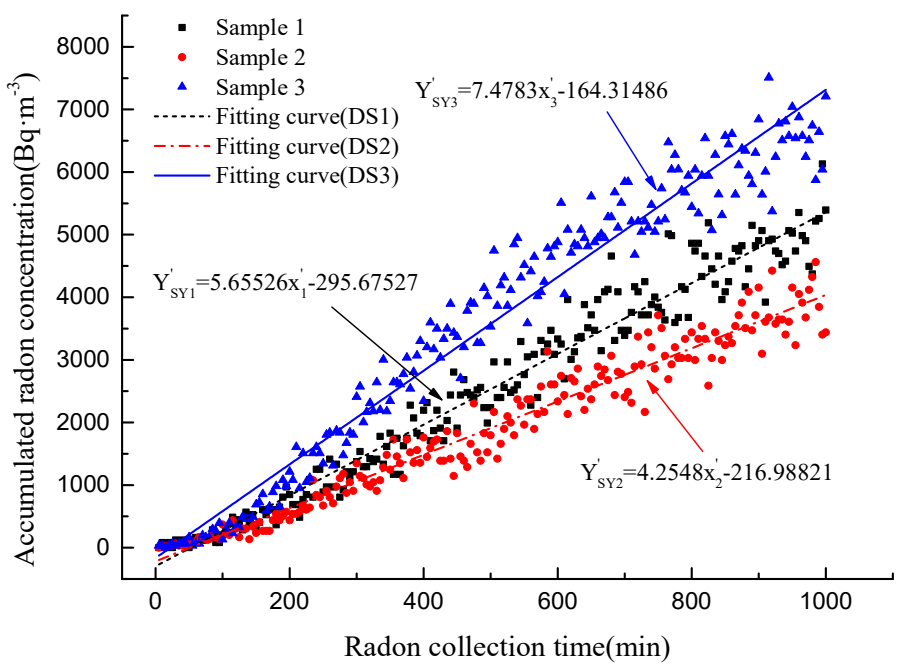

Figure 6. The variation curves of radon concentration and collection time from doubled-sided similar uranium samples with different proportions with a blank control group $(0 \mathrm{~Hz})$.

In Figures 5 and 6, the radon concentrations of the three proportions of single-sided and double-sided similar uranium samples with different ratios increased with the increase in the radon collecting time in the case of the blank group. In this paper, the blank control group was set as the test group without the effect of low frequency disturbance, and the corresponding testing vibration frequency was $0 \mathrm{~Hz}$. However, the linearly-increasing slope was not the same: The linear increasing slope of the radon exhalation concentration in sample 3 was the largest, the slope of $k_{3}$ (single- and double-sided) was 6.33405 and 7.4783. For sample 1, the slope of $k_{1}$ (single- and double-sided) was 5.0651 and 5.65526. The minimum incremental slope was found in sample 2, where the slope of $k_{2}$ (single- and double-sided) was 3.03321 and 4.2548. According to the results of the statistical analysis, the linear correlation of the radon concentration under the single-sided (and double-sided) testing conditions in sample 1, sample 2 and sample 3 were 0.96043 (0.96243), 0.93493 (0.95616) and 0.96557 (0.95992), respectively, indicating a good correlation between the fitting curves. There is a significant positive correlation between the radon concentration and the collection time of the radon under the single-sided and double-sided testing plan. As shown in Figure 7, the curves for the sample 3 radon concentration for the single-sided and double-sided sample nearly coincided until $600 \mathrm{~min}$, when the 
radon concentration tended to separate gradually. With the increase in time, the trend of radon concentration on the double-sided sample was higher than on the single-sided sample.

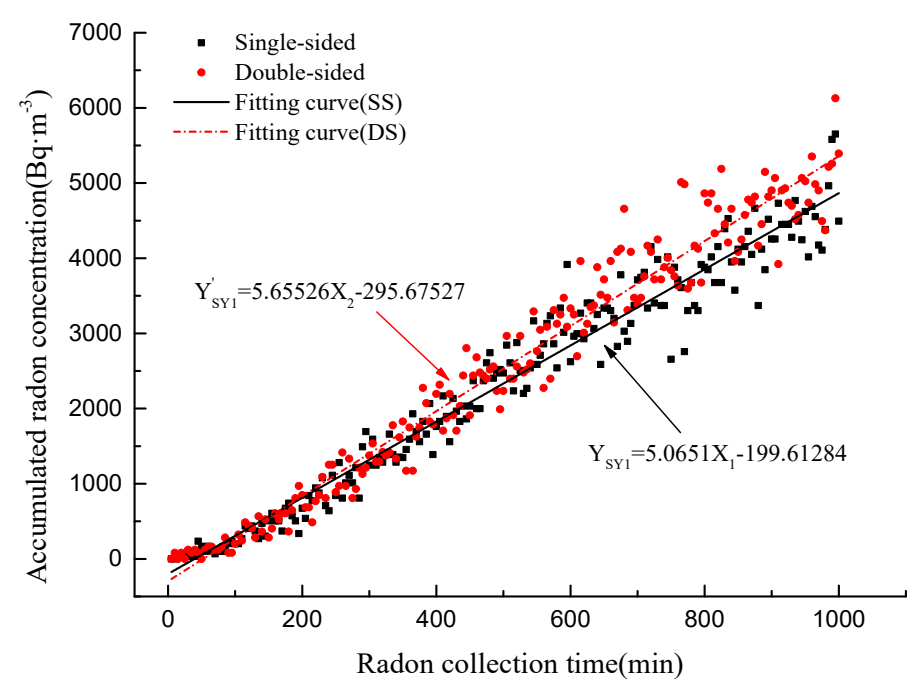

Figure 7. The variation curves of radon concentration and collection time from single-sided and doubled-sided similar uranium samples with fixed proportions.

\section{Analysis and Discussion}

\subsection{Radon Exhalation and Frequency}

According to Equation (1) to Equation (3), we have calculated the radon exhalation rate of the samples under different experimental vibration frequencies. Because of the limitation of the method of electrostatic collection, there was some mathematical error in the measurement data of RAD7 radon detector. We have fitted the curve of radon exhalation rate of each ratio sample and marked the error bar, and the fitting degree $\left(R^{2}\right)$ of the curve was all above 0.95 .

Figures 8 and 9 show the results described in the following. The amount of radon exhalation, speed of radon exhalation and time of exhalation was the lowest from 0 to $80 \mathrm{~Hz}$ disturbance, yet $60 \mathrm{~Hz}$ disturbance had the longest exhalation under the single-sided testing conditions. When the test frequency reached $70 \mathrm{~Hz}$, the trend of the radon exhalation rate began to change and decreased slowly with the increase of radon exhalation; however, the amount of radon exhaled increased greatly compared to the blank control group. The increase in the radon exhalation rate of the similar uranium sample was limited by the low-frequency disturbance after obtaining a certain frequency due to the physical characteristics of the rocks and the magnitude of the driving force.

The maximized radon exhalation rate of the test samples with the proportion ratios 1, 2 and 3 under the single-sided test plan were found in the same test frequency range $(60 \mathrm{~Hz})$, from $0.0879 \mathrm{~Bq} \cdot \mathrm{m}^{-2} \cdot \mathrm{s}^{-1}$ to $0.1278 \mathrm{~Bq} \cdot \mathrm{m}^{-2} \cdot \mathrm{s}^{-1}$. The radon exhalation rate of sample 3 at the low frequency vibration was higher than that of sample 2 and sample 1 . The average lifting rate was $26.8 \%$, which is comparable with the percentage of uranium mass (Sample 3, $0.0085>$ Sample 1, $0.0071>$ Sample 1, 0.0068) found in the physical and mechanical tests of the three samples mentioned above. Sample 3 was $87.9 \%$ similar to the blank control group. 


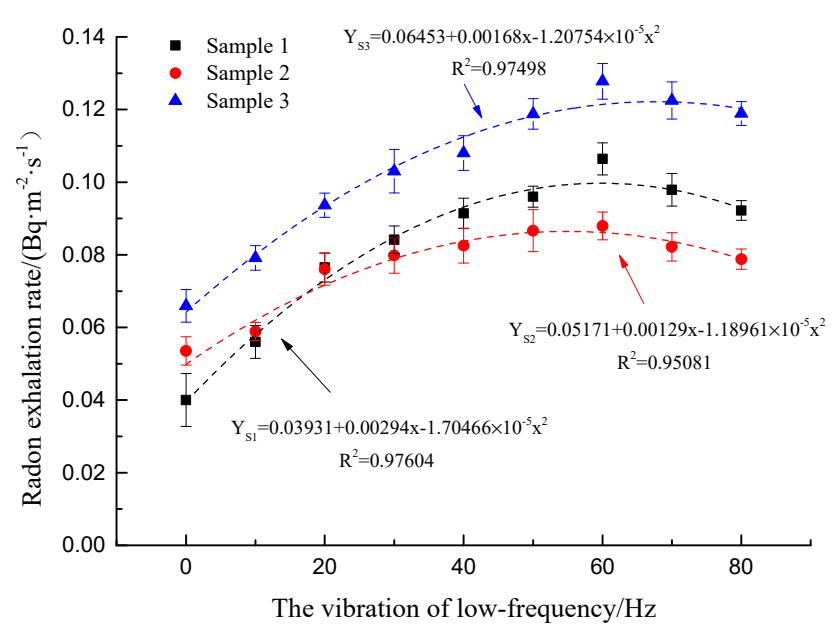

Figure 8. Curves of the radon exhalation rate of three types of similar uranium samples with different exciting vibration frequencies under the single-sided testing conditions.

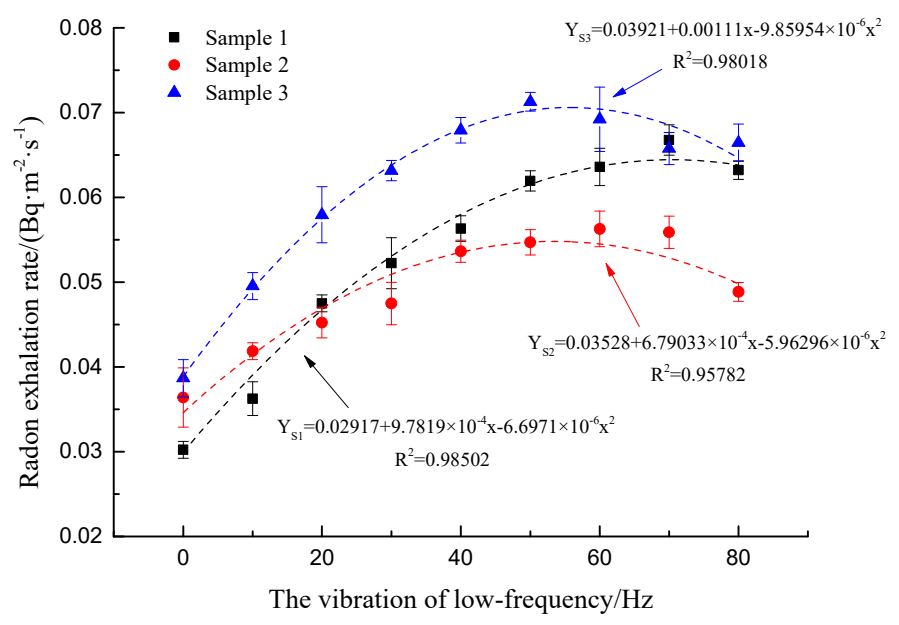

Figure 9. Curves of the radon exhalation rate of three types of similar uranium samples with different exciting vibration frequencies under the double-sided testing conditions.

By analyzing the curve of sample 1 and sample 2 in the above images, we can see that the fitting curves of sample $1\left(0.07602 \mathrm{~Bq} \cdot \mathrm{m}^{-2} \cdot \mathrm{s}^{-1}, 0.04523 \mathrm{~Bq} \cdot \mathrm{m}^{-2} \cdot \mathrm{s}^{-1}\right)$ and sample $2\left(0.07650 \mathrm{~Bq} \cdot \mathrm{m}^{-2} \cdot \mathrm{s}^{-1}\right.$, $0.04749 \mathrm{~Bq} \cdot \mathrm{m}^{-2} \cdot \mathrm{s}^{-1}$ ) converge in the $20 \mathrm{~Hz}$ test group under the single-sided and double-sided testing conditions. The radon exhalation rate of sample 1 was larger than that of sample 2 with the increase in the vibration frequency. There is an approximate intersection between the radon exhalation rate of sample $1\left(0.0667 \mathrm{~Bq} \cdot \mathrm{m}^{-2} \cdot \mathrm{s}^{-1}\right)$ and sample $3\left(0.0657 \mathrm{~Bq} \cdot \mathrm{m}^{-2} \cdot \mathrm{s}^{-1}\right)$ in the $70 \mathrm{~Hz}$ vibration testing group, as seen in Figure 8 , and the fitting predicted curve shows that the radon exhalation rate of both samples decreased slowly after reaching $80 \mathrm{~Hz}$.

\subsection{Damage Degree and Porosity}

According to the relevant literature [25-28], the damage degree $D$ of the similar uranium samples for the experiment was calculated using the following equation:

$$
D=1-\frac{E}{E_{0}}=1-\left(\frac{v}{v_{0}}\right)^{2}=1-K=1-(1-\beta)^{2}
$$

where $E_{0}$ is the elastic modulus of the sample before the application of low-frequency vibrations (MPa), $E$ is the equivalent elastic modulus of the sample after the application of low-frequency vibrations 
$(\mathrm{MPa}), v_{0}$ is the acoustic velocity before the application of low-frequency vibrations $\left(\mathrm{m} \cdot \mathrm{s}^{-1}\right), v$ is the acoustic velocity after the application of low-frequency vibrations $\left(\mathrm{m} \cdot \mathrm{s}^{-1}\right)$.

Taking sample 3 as an example, Figure 10 shows the relation between the average porosity of the test sample, the degree of rock damage and the vibration frequency to analyze the mechanism of the abnormal increase of the radon exhalation of the similar uranium samples under low-frequency vibrations. The figure is similar to the curve showing the change of frequency and radon exhalation rate. The porosity increased dramatically with the low-frequency vibrations, and when the frequency was close to $60 \mathrm{~Hz}$, a porosity of $4.835 \%$ was obtained, which was the maximum value. After this, the porosity decreased slowly. In the figure, the damage degree shows that the general trend is similar to the curve of the porosity, and when the sample was taken at $50 \mathrm{~Hz}$, the damage degree first reached the peak value of 0.0665 . The degree of the sample decreased slowly, which is accordance with the figure showing the radon exhalation rate for sample 3.

Figure 11 illustrates the relation between different numbers, frequencies and porosities, yet the errors of the different porosities were less than $8 \%$ under the different numbers and test scenarios. The change in the porosity of the similar uranium sample was deemed to be due to the change in the strain volume of the ore skeleton under the low-frequency vibrations. The certain mass sample was vibrated at the same driving force frequency during the test. It was concluded that the longer vibration time, the bigger the compressive strain of the ore under the low-frequency vibrations. The smaller the coefficient of the rock volume, the bigger the porosity of the test blocker.

Figure 12 shows the relation between the radon exhalation rate and comprehensive cumulative damage to the single-sided and double-sided group for sample 3 (single-sided: $R^{2}=0.93912$, double-sided: $R^{2}=0.97313$ ), which shows a certain linear connection. The damage to the rock induced by the excitation stress increased in a small range with a small excitation. The micro-fissure caused the lack of correlation. The radon exhalation rate and cumulative radon damage remained in the stable range and had obvious correlation due to the vibration loads in the later period.

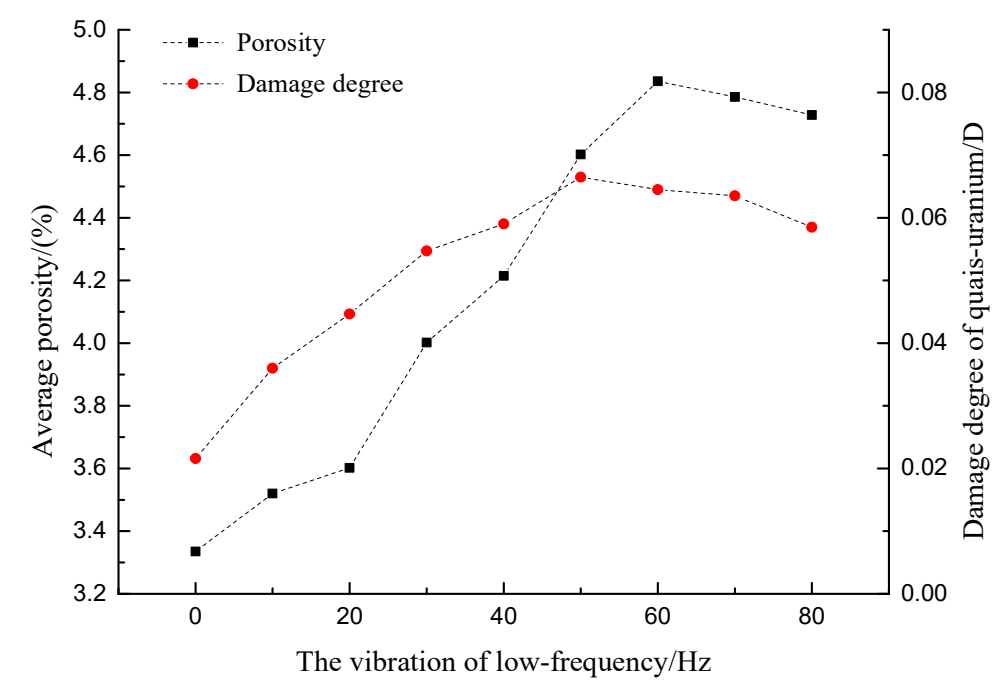

Figure 10. The relation between the cumulative damage degree and porosity with vibration frequency of Sample 3. 


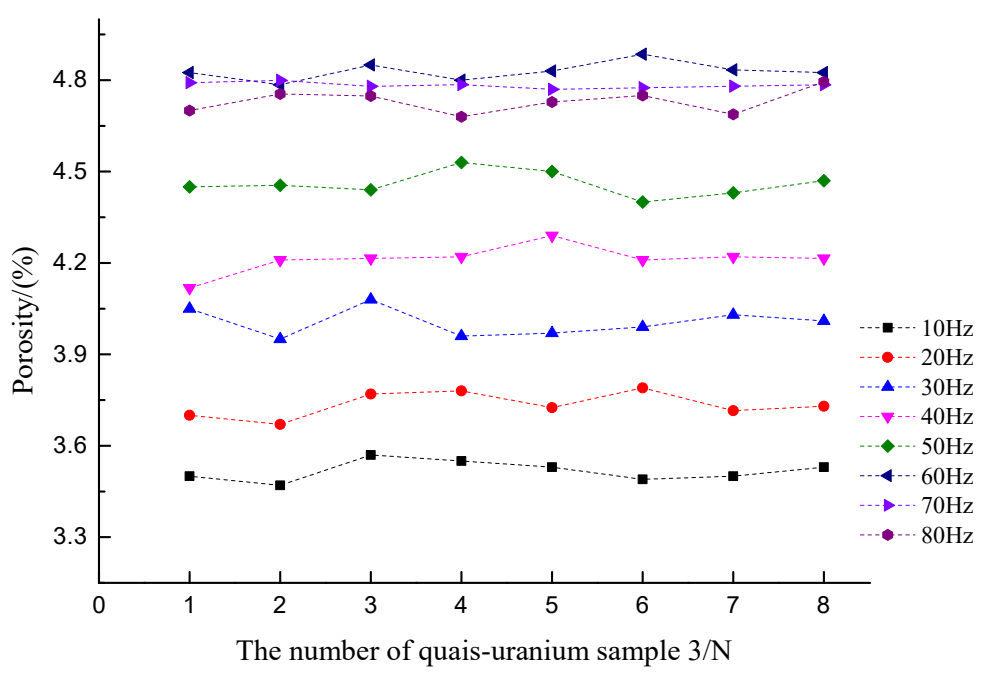

Figure 11. Porosity changes to different treatments of Sample 3 under different vibration frequencies.

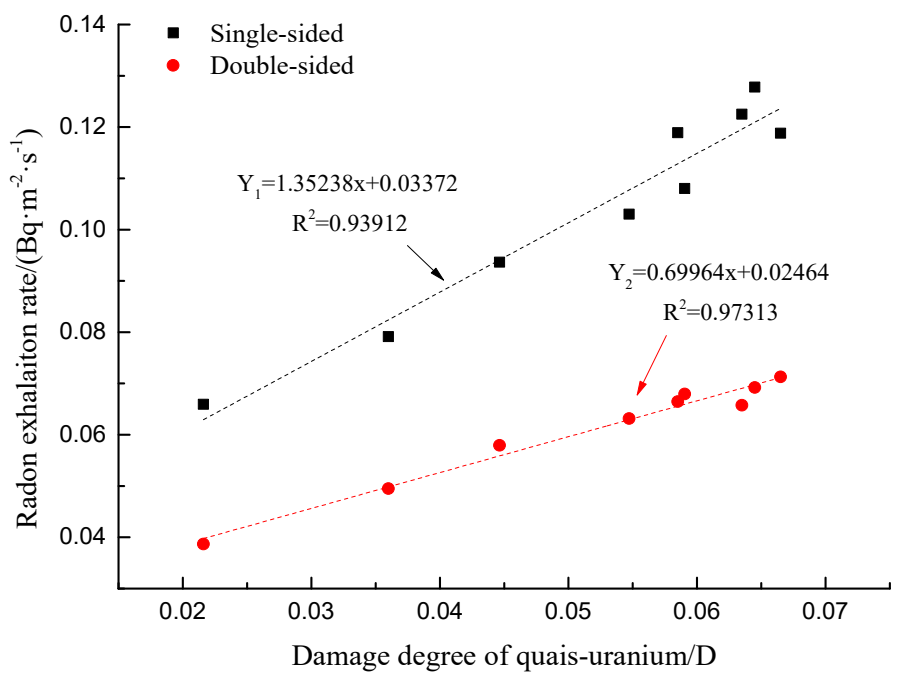

Figure 12. Relationship curve between radon exhalation rate and comprehensive damage degree of Sample 3.

In general, we can draw the following conclusions form the images shown in figure 10 to 12: As a dual porous emanium medium with pores and fractures, the concentration gradient was the most important motive force for radon migration in uranium ore. In the early stage of medium exposure to exhalation environment due to mining and other activities, the internal structure of uranium ore was changed due to low frequency vibration, and the molecular concentration of radon was very different between the surface of pores and fractures of uranium ore and the exhalation environment. Under the action of concentration gradient, radon diffused in the pores and exhaled from the surface of the medium, at the same time, the concentration difference between the pores and environment gradually reduced, and the radon exhalation rate and migration tended to be flat. Therefore, the influenced of low-frequency vibration on the law of radon exhalation was mainly achieved by affecting the change of concentration difference caused by the occurrence of pores and fractures in uranium ore. According to the experimental analysis, it is found that the effect has the characteristic of aging. 


\section{Conclusions}

Based on the closed chamber method, the radon concentration of similar uranium samples was measured under the conditions of single-sided and double-sided exposed uranium using an independently developed system. The relationship between the curve change of the radon exhalation rate and the average porosity of the rock mass was analyzed through a damage detection test of the rock mass and measurement of the average porosity of the sample. The effect of the low-frequency vibrations on the radon exhalation from similar uranium samples was in a certain range, but there was a bottleneck period in this range of influence. The fitting predicted curves of the radon exhalation rate were obtained through three sample tests, and the relationship between the curve and the damage distribution of the sample was analyzed by taking sample 3 as an example. The next step is to propose a solution and preventive measures for the low-frequency disturbances caused by the operation of machinery in uranium mining and rock mining; it will be the focus of future research work.

Author Contributions: X.-y.L. and Z.-q.C. conceived and designed the experiments; Z.-q.C. performed the experiments, analyzed the data, and wrote the paper, J-f.Y. contributed to the manuscript preparation and discussion, B.L. and C.-s.H. contributed to the discussion related to the low frequency vibrations on the radon exhalation and wrote-review to the paper, H.W. supervised the research and participated in the discussion.

Funding: This research was funded by National Natural Science Foundation of China (Grant No. 11475081).

Acknowledgments: The authors would like to thank the assistance of Penghua Hu and Wenhui Deng in improving the experiment scheme and enlightening discussions. We also acknowledge the anonymous reviews for their valuable comments.

Conflicts of Interest: The authors declare no conflict of interest.

\section{References}

1. Lian, B.G.; Liao, H.L.; Jin, H. The Hazards of Radon and its Precautions during the Underground Engineering. Chin. J. Radiol. Health 2014, 23, 143-144, 147. (In Chinese)

2. Chauhan, P.; Kumar, A. A Comparative Study of Indoor Radon Contributed by Diffusive and Advective Transport through Intact Concrete. Phys. Procedia 2015, 80, 109-112. [CrossRef]

3. Dutta, P.K.; Naskar, M.K.; Misa, O.P. Test of Strain Behavior Model with Radon Anomaly in Seismogenic Area: A Bayesian Melding Approach. Int. J. Geosci. 2012, 3, 126-132. [CrossRef]

4. Zafrir, H.; Barbosa, S.M.; Malik, U. Differentiation between the Effect of Temperature and Pressure on Radon within the Subsurface Geological Media. Radiat. Meas. 2013, 49, 39-56. [CrossRef]

5. Sakoda, A.; Ishimori, Y.; Hanamoto, K.; Kataoka, T.; Kawabe, A.; Yamaoka, K. Experimental and Modeling Studies of Grain Size and Moisture Content Effects on Radon Emanation. Radiat. Meas. 2010, 45, 204-210. [CrossRef]

6. Saâdi, Z.; Gay, D.; Guillevic, J.; Améon, R. EOS7Rn-A New TOUGH2 Module for Simulating Radon Emanation and Transport in the Subsurface. Comput. Geosci. 2014, 65, 72-83. [CrossRef]

7. Smetanová, I.; Holý, K.; Müllerová, M.; Polášková, A. The Effect of Meteorological Parameters on Radon Concentration in Borehole Air and Water. J. Radioanal. Nucl. Chem. 2010, 283, 101-109. [CrossRef]

8. Zhang, J.; Tuo, X.; Li, Z. The Migration of Radon in Different Air Pressure Experimental Study and the Average Velocity Estimation. Energy Procedia 2013, 39, 443-453. [CrossRef]

9. Jie, J.L. Experimental Study on Deterioration Mechanism of Rock under the Conditions of Freezing-Thawing Cycles in Cold Regions Based on NMR Technology. Ph.D. Thesis, Central South University, Changsha, China, 2012.

10. Hao, H.; Wu, C.; Seah, C.C. Numerical Analysis of Blast-Induced Stress Waves in a Rock Mass with Anisotropic Continuum Damage Models Part 2: Stochastic Approach. Rock Mech. Rock Eng. 2002, 35, 95-108. [CrossRef]

11. Nicolas, A.; Girault, F.; Schubnel, A.; Pill, E.; Passelegue, F.; Fortin, J. Radon Emanation from Brittle Fracturing in Granites under Upper Crustal Conditions. Geophysical Research Letters. 2015, 41, 5436-5443. [CrossRef]

12. Yin, L.B. Research on the Blast Vibration in an Underground Uranium-mine Based on Ls-Dyna. Master Thesis, Jiangxi University of Science and Technology, Ganzhou, China, 2015. (In Chinese) 
13. Zhang, D.S.; Zhang, W.; Ma, L.Q.; Wang, X.F.; Fan, G.W. Developments and Prospects of Detecting Mining-Indued Fracture in Overlying Strata by Radon. J. China Univ. Min. Technol. 2016, 45, 1082-1097. (In Chinese)

14. Yan, R.; Jiang, C.S.; Zhang, L.P. Study on Critical Slowing Down Phenomenon of Radon Concentrations in Water before the Wenchuan Ms 8.0 Earthquake Chinese. J. Geophys. 2011, 54, 1817-1826. (In Chinese)

15. Cai, S.W. Computer Simulation of Natural Frequency of Sheare. Coal Mine Mach. 2006, 27, 110-111. (In Chinese)

16. The National Standard of People's Republic of China. Seismic Ground Motion Parameters Zonation Map of China, GB 18306-2015; Standard Press of China: Beijing, China, 2015.

17. The Nuclear Industry Standard of People's Republic of China. Safety Requirements for Decommissioning of Nuclear Facilities, GB/T19597-2004; Standard Press of China: Beijing, China, 2004.

18. Külahci, F.; Inceöz, M.; Doğru, M.; Aksoy, E.; Baykara, O. Artificial Neural Network Model for Earthquake Prediction with Radon Monitoring. Appl. Radiat. Isot. Incl. Data Instrum. Methods Use Agric. Ind. Med. 2009, 67, 212-219. [CrossRef] [PubMed]

19. Mollo, S.; Tuccimei, P.; Heap, M.J.; Vinciguerra, S.; Soligo, M.; Castelluccio, M.; Scarlato, P.; Dingwell, D.B. Increase in Radon Emission Due to Rock Failure: An Experimental Study. Geophys. Res. Lett. 2011, 38, 130-137. [CrossRef]

20. Tan, K.X.; Wang, Q.L.; Liu, Z.H.; Hu, E.M. Nonlinear Dynamics of Flow-Reaction Coupling in Porous Media and Application to In Situ Leaching Uranium Mining. Int. J. Mod. Phys. B 2004, 18, 2663-2668. [CrossRef]

21. Schild, M.; Siegesmund, S.; Vollbrecht, A.; Mazurek, M. Characterization of granite matrix porosity and pore-space geometry by In Situ, and laboratory methods. Geophys. J. R. Astron. Soc. 2001, 146, 111-125. [CrossRef]

22. Dong, J.Y.; Yang, J.H.; Yang, G.X.; Wu, F.Q.; Liu, H.S. Research on Similar Material Proportioning test of Model Test Based on Orthogonal Design. J. China Coal Soc. 2012, 37, 44-49.

23. Zuo, B.C.; Chen, C.X.; Liu, C.H.; Shen, Q.; Xiao, G.F.; Liu, X.W. Research on Similar Material of Slope Simulation Experiment. Rock Soil Mech. 2004, 25, 1805-1808.

24. Li, S.; Feng, X.; Li, L.; Li, G. Research and Development of a New Similar for Solid-Fluid Coupling and its Application. Chin. J. Rock Mech. Eng. 2010, 29, 281-288.

25. Zhao, K.; Jin, J.F.; Wang, X.J.; Zhao, K. Study on rock damage and acoustic emission based on ultrasonic velocity test of rock specimen under uniaxial compression. Rock Soil Mech. 2007, 28, 2105-2109.

26. Yan, C.B. Blasting Damage Cumulative Effect of Rock Mass Based on Sound Velocity Variation. Rock Soil Mech. 2010, 31, 187-192.

27. Yilmaz, O.; Unlu, T. Three dimensional numerical rock damage analysis under blasting load. Tunn. Undergr. Space Technol. Incorp. Trenchless Technol. Res. 2013, 38, 266-278. [CrossRef]

28. Cao, W.; Zhao, H.; Zhang, L.; Zhang, Y. Damage statistical softening constitutive model for rock considering effect of damage threshold and its parameters determination method. Chin. J. Rock Mech. Eng. 2008, 27, 1148-1154.

(C) 2018 by the authors. Licensee MDPI, Basel, Switzerland. This article is an open access article distributed under the terms and conditions of the Creative Commons Attribution (CC BY) license (http:/ / creativecommons.org/licenses/by/4.0/). 